\title{
Montelukast as add-on therapy to $\beta$-agonists and late airway response
}

\author{
M. Rosewich, M.A. Rose, O. Eickmeier, M. Travaci, R. Kitz and S. Zielen
}

ABSTRACT: The present study investigated whether single-dose oral leukotriene receptor antagonists as add-on therapy to short-acting $\beta$-agonists, immediately after allergen challenge, block the late-phase airway response.

In total, 35 mild asthmatics (mean age 24 yrs, 19 males) sensitised for house dust mites underwent two courses of bronchial allergen challenge. After the early allergic response (EAR), subjects received salbutamol once and were randomly assigned to either $10 \mathrm{mg}$ of montelukast or placebo (double-blind crossover). To identify a late allergic response, forced expiratory volume in one second (FEV 1 ) was monitored over the following $8 \mathrm{~h}$. Baseline exhaled nitric oxide (NO) was determined ahead of each allergen challenge.

Baseline NO levels differed significantly depending on the reaction to allergen challenge. In total, 12 subjects showed no significant response, 11 only showed an EAR, and 12 had a dual response and underwent further analysis. The area under the FEV 1 time-response curve 3-8 $\mathrm{h}$ after bronchial allergen challenge was $-0.77 \pm 1.68$ from the pre-challenge values on montelukast compared with $-2.47 \pm 1.32$ on placebo. The baseline exhaled NO fraction of subjects without an EAR was significantly lower than of those presenting a dual response.

The results of the present study demonstrate that single-dose leukotriene receptor antagonists given orally right after the early allergic response can significantly inhibit the late allergic response after bronchial allergen challenge.

KEYWORDS: Asthma, bronchial allergen challenge, early asthmatic response, exhaled nitric oxide fraction, late asthmatic response, montelukast

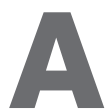
llergic asthma is characterised by bronchial hyperresponsiveness and airway inflammation. In asthmatic patients the fraction of nitric oxide in exhaled air $(\mathrm{Fe}, \mathrm{NO})$ is increased and correlates with asthma severity, sputum eosinophils and methacholine reactivity [1-3]. As inhaled allergens contribute to asthmatic inflammation, allergen challenge is a useful clinical tool to study the mechanisms underlying asthma. Bronchial allergen challenge in susceptible individuals leads to an early asthmatic response (EAR) due to cross-linking of surfacebound immunoglobulin (Ig)E on mast cells, causing the release of inflammatory mediators, such as histamine, prostaglandins and cysteinylleukotrienes (LTs). This mediator release results in smooth muscle contraction and mucosal oedema-triggering bronchoconstriction [4, 5]. The EAR, although caused by inflammatory mediators, can be completely inhibited or resolved by bronchodilators, such as $\beta_{2}$-agonists [6].

Approximately $30-50 \%$ of asthmatic subjects with a positive bronchial allergen challenge will experience a biphasic response to inhaled allergens [7]. The late asthmatic response (LAR), which may follow the EAR 3-8 h after allergen challenge, involves acute inflammation and swelling of the airway wall. The inflammatory process is driven by activated neutrophils, eosinophils, mast cells and T-lymphocytes, and leads to epithelial desquamation, altered mucociliary function and reduced clearance of respiratory tract secretions, thus resulting in airway obstruction [8-10]. This inflammation can be attenuated by corticosteroids, anti-IgE and anti-LTs, whereas $\beta$-agonists only have bronchodilatory capacities and lack anti-inflammatory effects.

The cysteinyl-LTs LTC4, LTD4 and LTE4 are not only potent bronchoconstrictors, but cause several biological actions in the pathogenesis of asthma, including increased vascular permeability, formation of oedema and enhanced mucus production [11]. These biological properties can be attenuated by anti-LT drugs. Reduction of inflammation and a decrease in $F_{\mathrm{e}, \mathrm{NO}}$ following montelukast treatment is thought to occur via two distinct mechanisms involving LTs, which are:
AFFILIATIONS

Dept of Paediatrics, Frankfurt

University, Frankfurt, Germany.

CORRESPONDENCE

M. Rosewich

Children's Hospital

Goethe University

Theodor Stern Kai 7

60590 Frankfurt

Germany

Fax: 496963016061

E-mail: Martin.Rosewich@kgu.de

Received:

May 102006

Accepted after revision:

January 092007

STATEMENT OF INTEREST

Statements of interest for all authors can be found at www.erj.ersjournals. com/misc/statements.shtml

European Respiratory Journal Print ISSN 0903-1936 Online ISSN 1399-3003 
direct inhibition at the receptor level; or inhibition of eosinophil recruitment into the lung, which indirectly reduces the capacity for further release of LTs $[12,13]$. However, the mechanisms by which montelukast modulates nitric oxide (NO) production are not yet completely understood.

Previous studies have shown that montelukast attenuates both early- and late-phase responses to aspirin [14], exerciseinduced bronchoconstriction [15] and allergen challenge [16], in both children [17] and adults [18]. Furthermore, DOCKHORN et al. [19] were able to show a quick onset of action for single doses of i.v. and oral montelukast. Orally administered montelukast led to a significant increase in the forced expiratory volume in one second (FEV1) within $2 \mathrm{~h}$, suggesting LT receptor antagonists (LTRA) as a treatment option in acute asthma.

However, there have been no studies evaluating the acute effects of a single dose of oral montelukast in a bronchial allergen challenge model. The present study sought to evaluate the acute effects of montelukast on the LAR after allergen exposure in adults with house dust mite-induced asthma by using a well-characterised allergen challenge model.

\section{METHODS}

\section{Subjects}

In total, 35 atopic adults (19 males; mean (range) age 24 (18-31) yrs) with mild and, at the time of the study, stable, physician-diagnosed asthma (FEV1 $\geqslant 80 \%$, vital capacity $\geqslant 80 \%$ ) were recruited from the campus population (Frankfurt University, Frankfurt, Germany) by means of public posting. All subjects were sensitised to house dust mite (IgE specific for Dermatophagoides farinae at least radioallergosorbent test (RAST) class 2) and had a history of episodic asthma (table 1).

Subjects were free of controller therapy (including long-lasting $\beta$-agonists, anticholinergics, theophylline, oral and inhaled corticosteroids, cromoglycate, antihistamines, and LT-antagonists) 8 weeks before and during the study. Seven of the subjects smoked occasionally or regularly (1-15 cigarettes."' day $^{-1}$; table 1) but did not change their smoking habits during the study. None of the subjects used medication that could influence the results of this study. All subjects were in good clinical condition; none had experienced a respiratory tract infection within 2 weeks before and during the study, or suffered from any respiratory complaints on the day of the study. All patients supplied written informed consent prior to the study. Human experimentation guidelines of good clinical practice, the German Drug Act and the declaration of Helsinki were followed in the conduct of clinical research. Local ethics committee approval was obtained.

\section{Study design}

The study was a randomised, double-blind, single-dose, placebo-controlled, crossover trial with a washout period of $\geqslant 2$ weeks. Subjects attended the department for three visits (fig. 1). On the first visit, entry criteria were assessed by interviewing the subjects, performing a physical examination, and drawing a venous blood sample for further analysis (total IgE, specific IgE (RAST), blood count).
On the second visit, house dust mite sensitised subjects were checked for signs of airway infection, underwent spirometry and $\mathrm{Fe}$,NO was determined. Only healthy subjects with an FEV1 and forced vital capacity (FVC) $>80 \%$ were challenged as explained later.

Subjects underwent spirometry $10 \mathrm{~min}$ after completion of the final allergen dosing. When an EAR (decrease in FEV1 $>20 \%$ ) or a clinical reaction occurred, subjects received one puff of salbutamol $(0.1 \mathrm{mg})$ and either montelukast $(2 \times 5 \mathrm{mg}$ tablets $)$ or matching placebo immediately. During the following $8 \mathrm{~h}$, FEV1 was monitored hourly. If subjects showed an LAR (FEV1 drop $>15 \%$ 6-8 $\mathrm{h}$ after bronchial allergen challenge), they received a long-lasting $\beta_{2}$-agonist (formoterol, $12 \mu \mathrm{g}$, one puff) after finishing the test. On the third visit $\geqslant 14$ days later (1442 days), the same procedure was repeated, crossing-over montelukast and placebo.

\section{Lung function tests}

Baseline spirometry (before inhalation of sterile saline $0.9 \%$ and before allergen challenge), was performed with the MasterScreen ${ }^{\circledR}$ bodyplethysmograph (VIASYS Healthcare GmbH, Hoechberg, Germany). Before and $0-8 \mathrm{~h}$ after bronchial allergen challenge, subjects measured FEV1 hourly using the SpiroPro (VIASYS Healthcare GmbH).

\section{Measurement of exhaled NO}

Measurements of exhalative $\mathrm{NO}$ were carried out using the NIOX $_{\circledR}$ (Aerocrine, Solna, Sweden). The NIOX $_{\circledast}$ measures NO in exhaled air according to American Thoracic Society guidelines [20]. This chemiluminescence gas analyser is sensitive to $\mathrm{NO}$ at concentrations ranging $1.5-200 \mathrm{ppb}$ with a deviation from mean value of $\pm 2.5 \mathrm{ppb}$ at $\mathrm{NO}<50 \mathrm{ppb}$ or $\pm 5 \%$ of the measured value at $>50 \mathrm{ppb}$.

\section{Allergen inhalation challenge protocol}

Solutions of D. farinae allergen extract (Allergopharma, Reinbek, Germany) were prepared according to the instruction manual. The lyophilised D. farinae allergen extract was resuspended in the solution provided by the manufacturer (containing sodium, phenol and water) resulting in aliquots of $5,000 \mathrm{mg} \cdot \mathrm{mL}^{-1}$; aliquots were stored immediately after preparation at $4{ }^{\circ} \mathrm{C}$ until applied. All subjects were exposed in a single-blinded fashion by inhalation of sterile saline $0.9 \%$ followed $5 \mathrm{~min}$ later by increasing concentrations of $D$. farinae. The solutions were delivered via a medic aid nebuliser and the aerosol provocation system $\mathrm{APS}_{\mathbb{R}}$ powered by compressed air (VIASYS Healthcare GmbH). This system calculates the administered dose by breath from a constant flow and the inspiration time of any breath cycle, thus calculating the exact dose to be administered automatically. Mouthpieces and nebulisers were changed after each subject to avoid cross contamination. The doses of inhaled $D$. farinae were increased every $8 \mathrm{~min}$ according to the following pattern, from step 1 to 8: $0,10,20,40,80,160,320$ and $640 \mathrm{mg}$. Thus, the entire protocol delivered cumulative doses of $0,10,30,70,150,310$, 630 and 1,270 mg. This procedure had been developed in earlier studies and was found to be extremely safe, avoiding overdosing and detecting potential side effects as early as possible [21]. The challenge test was stopped when any of the following criteria were met: 1) the FEV1 decreased at least $20 \%$ 
TABLE 1 Baseline characteristics of patients and applied allergen doses

\begin{tabular}{|c|c|c|c|c|c|c|c|c|c|}
\hline & \multirow[t]{2}{*}{ Sex } & \multirow[t]{2}{*}{ Age yrs } & \multirow[t]{2}{*}{ Smoker } & \multirow[t]{2}{*}{ Specific IgE } & \multirow[t]{2}{*}{ vc \% } & \multirow[t]{2}{*}{ FEV $_{1} \%$} & \multirow[t]{2}{*}{ eNO ppb } & \multicolumn{2}{|c|}{ Allergen dose mg } \\
\hline & & & & & & & & Montelukast & Placebo \\
\hline \multicolumn{10}{|c|}{ Subjects with no } \\
\hline 1 & M & 28 & Yes & 5.75 & 89.46 & 98.53 & 12.4 & 630 & 150 \\
\hline 8 & $\mathrm{~F}$ & 27 & No & 5.53 & 108.63 & 116.28 & 27.8 & 630 & 1144 \\
\hline 9 & M & 25 & No & 29.63 & 85.60 & 93.18 & 22.6 & 1090 & 805 \\
\hline 10 & $\mathrm{~F}$ & 21 & Yes & 7.10 & 94.54 & 96.75 & 11.4 & 775 & 521 \\
\hline 12 & $\mathrm{~F}$ & 24 & No & 2.44 & 90.21 & 91.84 & 23.2 & 992 & 996 \\
\hline 14 & M & 27 & No & 1.16 & 90.95 & 102.48 & 18.5 & 630 & 630 \\
\hline 16 & $\mathrm{~F}$ & 25 & Yes & 1.93 & 109.56 & 122.41 & 15.8 & 1140 & 1226 \\
\hline \multicolumn{10}{|c|}{ Subjects with no } \\
\hline 2 & M & 22 & No & 16.27 & 97.48 & 112.18 & 23.4 & 310 & 630 \\
\hline 6 & M & 21 & No & 7.89 & 93.83 & 105.49 & 199.2 & 150 & 70 \\
\hline 11 & M & 28 & No & 14.95 & 85.61 & 83.85 & 14.0 & 630 & 150 \\
\hline 15 & M & 21 & No & 15.64 & 113.01 & 119.71 & 28.6 & 630 & 150 \\
\hline 24 & $\mathrm{~F}$ & 21 & No & 65.80 & 112.01 & 115.97 & 14.9 & 960 & 965 \\
\hline 25 & M & 23 & No & 25.60 & 87.06 & 98.33 & 38.0 & 240 & 240 \\
\hline 26 & $\mathrm{~F}$ & 22 & No & 2.86 & 104.20 & 95.50 & 9.1 & 560 & 943 \\
\hline 28 & $\mathrm{~F}$ & 22 & No & 37.50 & 112.34 & 128.53 & 17.5 & 1024 & 240 \\
\hline 31 & M & 21 & No & 64.60 & 115.14 & 116.13 & 82.5 & 240 & 560 \\
\hline 13 & $M$ & 31 & No & 4.98 & 114.09 & 116.67 & 60.9 & 150 & 630 \\
\hline 17 & $M$ & 30 & No & 5.57 & 97.06 & 113.55 & 27.2 & 1263 & 640 \\
\hline 18 & $\mathrm{~F}$ & 18 & Yes & 42.54 & 135.09 & 138.83 & 11.6 & 1250 & 150 \\
\hline 20 & $\mathrm{~F}$ & 31 & No & 18.41 & 76.78 & 88.36 & 19.7 & 1270 & 1270 \\
\hline 23 & $\mathrm{~F}$ & 24 & No & 100.00 & 129.95 & 133.14 & 153.8 & 560 & 240 \\
\hline 27 & $M$ & 21 & No & 26.90 & 119.61 & 110.00 & 122.6 & 80 & 560 \\
\hline 29 & M & 22 & Yes & 61.20 & 111.35 & 107.31 & 99.4 & 240 & 80 \\
\hline 30 & $M$ & 24 & No & 68.10 & 104.45 & 97.02 & 25.8 & 240 & 240 \\
\hline 32 & $M$ & 30 & No & 14.10 & 111.70 & 114.92 & 40.4 & 560 & 854.3 \\
\hline 33 & $\mathrm{~F}$ & 25 & No & 85.90 & 106.61 & 117.93 & 55.8 & 240 & 560 \\
\hline Mean & & & & 30.05 & 109.0 & 111.80 & 37.3 & 619.42 & 500.36 \\
\hline
\end{tabular}

Ig: immunoglobulin; VC: vital capacity; FEV1: forced expiratory volume in one second; eNO: exhaled nitric oxide; EAR: early allergic response; LAR: late allergic response; M: male; F: female

from individual baseline (EAR); 2) significant clinical complaints were reported by the subjects (e.g. chest pain); 3) a cumulative dose of $1,270 \mathrm{mg}$ had been achieved. Clinical monitoring accompanied each provocation for $\geqslant 8 \mathrm{~h}$, subjects could then leave the hospital, remaining in touch via telephone with a physician involved in the study.

\section{End-points and statistical analysis}

The primary end-point was the area under the FEV1 timeresponse curve (FEV1-AUC) 3-8 h after bronchial allergen challenge in those subjects with an EAR and LAR (dual response) to bronchial allergen challenge. As established in the literature, it is given dimensionless. To identify a dual 


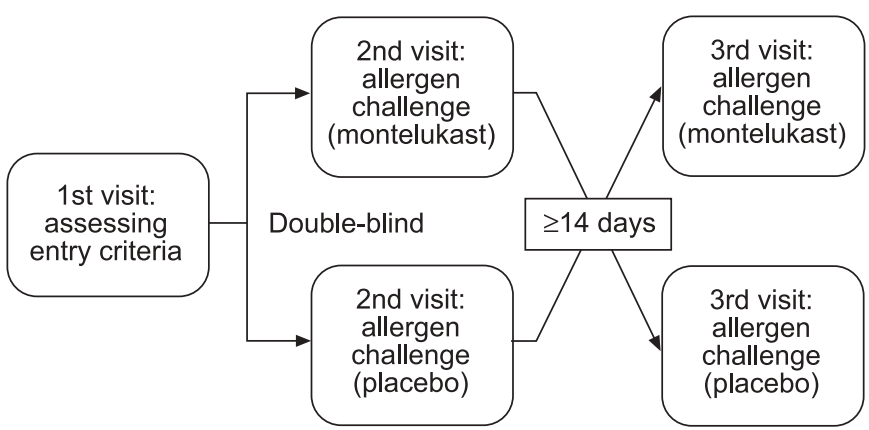

FIGURE 1. Flow chart demonstrating the study design.

response, a significant EAR was defined as a decrease in FEV1 $>20 \%$ and a significant LAR was defined as a drop in the FEV1 $>15 \%$. The Wilcoxon matched pairs test was used to analyse differences in FEV1 values, Fe,NO levels were compared with the Mann-Whitney U-test. The level of statistical significance was set at $\mathrm{p}<0.05$.

\section{RESULTS}

FEV 1

In total, 35 subjects underwent two allergen challenge tests and completed the study. Of these, 12 subjects showed no significant EAR on one or both study days and were excluded from further analysis. Of the remaining 23 subjects, 12 (52\%) had a dual response (EAR and LAR) and were therefore analysed. There were no significant differences in baseline lung function between these three groups (table 1).

In eight out of 12 subjects the dose applied varied only within one dosage step, thus making the provocation schedule comparable. Six out of 12 subjects tolerated higher house dust mite doses on the montelukast day.

The difference in FEV1 from baseline values 3-8 $\mathrm{h}$ after allergen challenge was expressed as the area under the dimensionless FEV1-AUC (fig. 2). The FEV1 values of each patient during the LAR (3-8 h after bronchial allergen challenge) on placebo were compared with the results from patients on montelukast. One of the subjects with a dual response had a smaller decrease of FEV1-AUC on placebo than on montelukast, while 11 showed better results with montelukast. The FEV1-AUC of the 12 subjects receiving placebo was $-2.47 \pm 1.32$ of the pre-challenge values compared with $-0.768 \pm 1.68$ receiving montelukast $(p<0.005)$. In order to control for an influence of the allergen dose applied, an additional subgroup analysis was carried out of those who received the same allergen does on both visits. Subjects treated with montelukast experienced significantly less FEV1 decrease than those after placebo (FEV1-AUC; $\mathrm{p}=0.0391$ ). When pooling data from all study subjects, a trend of higher FEV1 values was also found after montelukast (mean $98.2 \pm 8.6$ versus $94.9 \pm 7.7 \%$ ), which did not reach statistical significance. Additionally, the baseline FEV1 values of each patient were matched with the greatest decrease in FEV1 6-8 h after bronchial allergen challenge following placebo or montelukast, respectively (fig. 3).

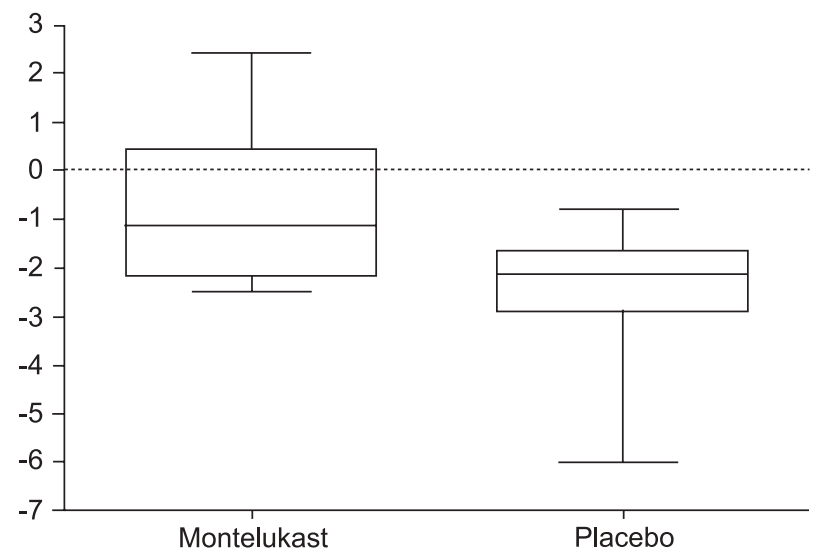

FIGURE 2. Area under the forced expiratory volume in one second timeresponse curve 3-8 $\mathrm{h}$ after bronchial allergen challenge, for montelukast and placebo respectively (shown are maximum and minimum values, the 95\% confidence interval and the median).

\section{Exhaled NO fraction}

In total, 35 subjects performed baseline $\mathrm{Fe}, \mathrm{NO}$ measurements. The 12 subjects showing no EAR on one or both study days had baseline NO levels of $21.0 \mathrm{ppb}$ (95\% confidence interval (CI) 13.9-28.1) compared with $39.0 \mathrm{ppb}$ (95\% CI 2.62-75.4) in those subjects with an EAR on both study days and $56.4 \mathrm{ppb}$ (95\% CI 27.6-85.2) of the subjects with a dual response. The comparison of the subjects without an EAR and those with a dual response reached statistical significance $(p<0.05)$.

There was no correlation between baseline $\mathrm{Fe}, \mathrm{NO}$ and response to montelukast in the subjects of the present study, although there was a slight trend towards higher baseline $F$ e,NO values in the subjects with a poor response to montelukast.

In a subgroup of subjects $(n=8), F e, N O$ was followed up until $24 \mathrm{~h}$ after bronchial allergen challenge. There was no significant difference between pre-challenge $\mathrm{Fe}, \mathrm{NO}$ (median (range); verum: 24.3 (15-120); placebo: 34.0 (12-82)) and Fe,NO after $8 \mathrm{~h}$ (verum: 36.5 (12-150); placebo: 27.1 (9-60)),

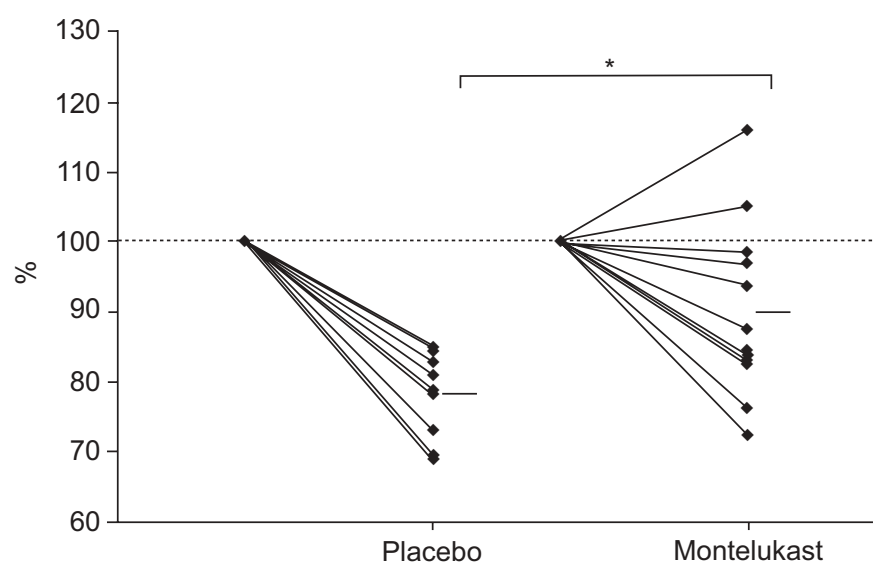

FIGURE 3. Comparison of individual forced expiratory volume in one second values in patients on placebo and montelukast respectively: baseline (100\%) versus late asthmatic response (maximum per cent fall 6-8 $\mathrm{h}$ after bronchial challenge). Mean values are marked. *: $p<0.05$. 
respectively. After $24 \mathrm{~h}$ there was a significant increase in both groups (verum: 73.6 (30-219); placebo: 90.8 (29-248)), but the current authors were not able to show a significant difference between verum and placebo at any time point.

\section{DISCUSSION}

Cysteinyl-LTs play a pivotal role in different types of inflammatory lung diseases including allergic asthma [22]. They are particularly involved in the mechanisms leading to bronchoconstriction during the early and late asthmatic response. There are also sufficient data demonstrating that activation of LT receptors results in induction of NO release [23-25]. Studies on an effect of fluticasone or budesonide compared with montelukast revealed a positive impact of all three substances on an early asthmatic response, with steroids being superior in improving bronchial hyperresponsiveness $[26,27]$. Additionally, a positive impact of inhaled corticosteroids on the late asthmatic response could also be demonstrated [28]. Keeping the side-effects of steroids in mind, the goal of the present study was to further investigate montelukast as an add-on option to $\beta$-mimetics in mild bronchial asthma.

Subjects with a history of mild allergic asthma and no need for a controller therapy (Global Initiative for Asthma (GINA) I) were challenged twice with house dust mite allergen. Of these, $23(65.7 \%)$ subjects had an EAR on both study days (decrease in $\left.\mathrm{FEV}_{1}>20 \%\right)$ and only $12(34.3 \%)$ had a dual response. Furthermore, as baseline $\mathrm{Fe}$,NO levels differed significantly among the patients, the results suggest that baseline $F_{e, N O}$ might be useful to distinguish between subjects who develop an LAR from the subjects who do not. This is in keeping with the findings of KHARITONOV et al. [29].

The present study is the first to evaluate the acute effects of a single dose of montelukast on airway function when being given orally after an early asthmatic response. It was shown that montelukast significantly blocked the late asthmatic response in subjects responding dually to an allergen challenge. These results suggest an acute inhibiting effect on an LT-driven inflammatory process as the LAR generally leads to bronchoconstriction due to inflammation. Furthermore, the results suggest a rapid onset of action of montelukast even when only administered once orally. This is of clinical value, as many patients use a short-acting $\beta_{2}$-agonist (SABA) for symptom relief after allergen exposure. In the absence of a preventive effect, they have to be administered repeatedly once LAR occurs. Thus, LTRA offer a new therapeutic option in this setting. However, it is known from the literature that there are some subjects who have little response to LTs. The present findings concur well with these results. It is essential to determine predictors for a positive response to montelukast, as the rapid onset of montelukast action indicates that LTRA are suitable medications for asthma patients.

SZEFLER et al. [30] recently identified the female sex, a greater decrease in FEV1 from baseline, young age or a short duration of the disease, and the FEV1/FVC ratio as predictors for a better LTRA response. In contrast, allergies and high levels of $\mathrm{Fe}$,NO indicated a response to corticosteroids. The current authors could not confirm the positive and negative predictive values of those parameters with the restriction of a small sample size not only in the study by SzEFLER et al. [30], but also in the present study.

The current authors and other investigators showed that single doses of montelukast initiated sustained effects. DOCKHORN et al. [19] compared the kinetics of i.v. montelukast with oral montelukast and placebo in patients with severe asthma. They were able to demonstrate an effect of montelukast on FEV1 when administered intravenously within $1 \mathrm{~h}$. This was confirmed by other authors [31-34]. Additionally, they showed that a single dose of oral montelukast led to a significant increase in FEV1 within 2-3 h. Other studies have shown the protective effect of an orally administered single-dose LTRA in exercise-induced asthma in children and adults [13, 18]. In these studies, montelukast was demonstrated to improve pulmonary function within 3-12 h after ingestion. This effect of a single-dose lasted up to $24 \mathrm{~h}$. In other trials, the onset of action of montelukast applied orally was in the range of $1-$ 3 days $[12,15,16]$. Furthermore, it was suggested that LTRA are able to reduce both the early and late asthmatic response in allergic subjects when given before allergen challenge [32].

The aim of the present study was to investigate a therapeutic option to better control late asthmatic symptoms in mild allergic asthmatics. The property of SABA to potentially attenuate the LAR has been studied extensively and was found to have no sustained effect on bronchial obstruction after $4-8 \mathrm{~h}$. It is possible that a very mild and early LAR could be missed in the setting of the present study. Conversely, the placebo control would have had the potential to distinguish when a more pronounced LAR occurred. Moreover, the current authors found it not ethically justified to withhold SABA in this setting. Thus, SABA was routinely provided after the challenge, which is a routine procedure according to GINA guidelines and ensures the patients' safety. Despite this manoeuvre being performed in all subjects, better lung function values could clearly be demonstrated in the montelukast group.

The present study was not designed as a therapeutic trial but to provide pharmacological proof of concept. Given the heterogeneity of some of the individual responses, it is estimated that the relatively small study population raises the possibility of unrecognised type 1 and type 2 statistical errors, and that larger comparative investigations will be needed to confirm the effect of a single dose of oral montelukast. Future trials will have to evaluate which patients profit and if this effect shown is only due to the antiobstructive effect of montelukast, or whether additional antiinflammatory mechanisms attenuating the LAR will be detectable.

To conclude, a bronchodilative effect of montelukast added to salbutamol was determined, with an onset of action of 3-8 h in an allergen challenge model. The present study could not show an anti-inflammatory effect. Further studies are necessary to evaluate the clinical efficacy of montelukast given on demand.

\section{REFERENCES}

1 Jatakanon A, Lim S, Kharitonov SA, Chung KF, Barnes PJ. Correlation between exhaled nitric oxide, sputum eosinophils, 
and methacholine responsiveness in patients with mild asthma. Thorax 1998; 53: 91-95.

2 Jatakanon A, Lim S, Chung KF, Barnes PJ. An inhaled steroid improves markers of airway inflammation in patients with mild asthma. Eur Respir J 1998; 12: 1084-1088.

3 Kharitonov SA, Yates D, Robbins RA, Logan-Sinclair R, Shinebourne EA, Barnes PJ. Increased nitric oxide in exhaled air of asthmatic patients. Lancet 1994; 343: 133-135.

4 Befus D. The role of the mast cell in allergic bronchospasm. Can J Physiol Pharmacol 1987; 65: 435-441.

5 Cockcroft DW. Mechanism of perennial allergic asthma. Lancet 1983; 2: 253-256.

6 Sears MR. Asthma treatment: inhaled beta-agonists. Can Respir J 1998; 5: Suppl. A, 54A-59A.

7 Robertson DG, Kerigan AT, Hargreave FE, Dolovich J. Late asthmatic responses induced by ragweed pollen allergen. J Allergy Clin Immunol 1974; 54: 244-254.

8 Pelikan Z, Pelikan-Filipek M. The late asthmatic response to allergen challenge - Part I. Ann Allergy 1986; 56: 414-420.

9 Pelikan Z, Pelikan-Filipek M. The late asthmatic response to allergen challenge - Part II. Ann Allergy 1986; 56: 421-435.

10 Dolovich J, Hargreave FE, Jordana M, Denburg J. Latephase airway reaction and inflammation. J Allergy Clin Immunol 1989; 83: 521-524.

11 Henderson WR Jr. Role of leukotrienes in asthma. Ann Allergy 1994; 72: 272-278.

12 Perry TT, Corren J, Philip G, et al. Protective effect of montelukast on lower and upper respiratory tract responses to short-term cat allergen exposure. Ann Allergy Asthma Immunol 2004; 93: 431-438.

13 Coreno A, Skowronski M, Kotaru C, McFadden ER Jr. Comparative effects of long-acting $\beta_{2}$-agonists, leukotriene receptor antagonists, and a 5-lipoxygenase inhibitor on exercise-induced asthma. J Allergy Clin Immunol 2000; 106: 500-506.

14 Dahlen SE, Malmstrom K, Nizankowska E, et al. Improvement of aspirin-intolerant asthma by montelukast, a leukotriene antagonist: a randomised, double-blind, placebo-controlled trial. Am J Respir Crit Care Med 2002; 165: 9-14.

15 Leff JA, Busse WW, Pearlman D, et al. Montelukast, a leukotriene-receptor antagonist, for the treatment of mild asthma and exercise-induced bronchoconstriction. $N$ Engl J Med 1998; 339: 147-152.

16 Diamant Z, Grootendorst DC, Veselic-Charvat M, et al. The effect of montelukast (MK-0476), a cysteinyl leukotriene receptor antagonist, on allergen-induced airway responses and sputum cell counts in asthma. Clin Exp Allergy 1999; 29: 42-51.

17 Phipatanakul W, Nowak-Wegrzyn A, Eggleston PA, et al. The efficacy of montelukast in the treatment of cat allergen-induced asthma in children. J Allergy Clin Immunol 2002; 109: 794-799.

18 Cylly A, Kara A, Ozdemir T, Ogus C, Gulkesen KH. Effects of oral montelukast on airway function in acute asthma. Respir Med 2003; 97: 533-536.

19 Dockhorn RJ, Baumgartner RA, Leff JA, et al. Comparison of the effects of intravenous and oral montelukast on airway function: a double blind, placebo controlled, three period, crossover study in asthmatic patients. Thorax 2000; 55: 260-265.

20 Recommendations for standardized procedures for the online and off-line measurement of exhaled lower nitric oxide and nasal nitric oxide in adults and children - 1999. The official statement of the American Thoracic Society was adopted by the ATS Board of Directors, July 1999. Am J Respir Crit Care Med 1999; 160: 2104-2117.

21 Wonne R, Hofmann D, Posselt HG, Stover B, Bender SW. Bronchial allergy in cystic fibrosis. Clin Allergy 1985; 15: 455-463.

22 O'Driscoll BR, Kay AB. Leukotrienes and lung disease. Thorax 1982; 37: 241-245.

23 De Sanctis GT, MacLean JA, Hamada K, et al. Contribution of nitric oxide synthases 1,2 , and 3 to airway hyperresponsiveness and inflammation in a murine model of asthma. $J$ Exp Med 1999; 189: 1621-1630.

24 Menard G, Bissonnette EY. Priming of alveolar macrophages by leukotriene $\mathrm{D}_{4}$ : potentiation of inflammation. Am J Respir Cell Mol Biol 2000; 23: 572-577.

25 Walch L, Norel X, Gascard JP, Brink C. Functional studies of leukotriene receptors in vascular tissues. Am J Respir Crit Care Med 2000; 161: S107-S111.

26 Palmqvist M, Bruce C, Sjostrand M, Arvidsson P, Lotvall J. Differential effects of fluticasone and montelukast on allergen-induced asthma. Allergy 2005; 60: 65-70.

27 Leigh R, Vethanayagam D, Yoshida M, et al. Effects of montelukast and budesonide on airway responses and airway inflammation in asthma. Am J Respir Crit Care Med 2002; 166: 1212-1217.

28 Paggiaro PL, Dente FL, Morelli MC, et al. Postallergen induced budesonide reduces late asthmatic response and inhibits the associated increase of airway responsiveness to methacholine in asthmatics. Am J Respir Crit Care Med 1994; 149: 1447-1451.

29 Kharitonov SA, O'Connor BJ, Evans DJ, Barnes PJ. Allergen-induced late asthmatic reactions are associated with elevation of exhaled nitric oxide. Am J Respir Crit Care Med 1995; 151: 1894-1899.

30 Szefler SJ, Phillips BR, Martinez FD, et al. Characterization of within-subject responses to fluticasone and montelukast in childhood asthma. J Allergy Clin Immunol 2005; 115: 233-242.

31 Singh SD, Allen DJ. Intravenous montelukast. Thorax 2000; 55: 1070 .

32 Camargo CA Jr, Smithline HA, Malice MP, Green SA, Reiss TF. A randomized controlled trial of intravenous montelukast in acute asthma. Am J Respir Crit Care Med 2003; 167: 528-533.

33 Melo RE, Sole D, Naspitz CK. Exercise-induced bronchoconstriction in children: montelukast attenuates the immediate-phase and late-phase responses. J Allergy Clin Immunol 2003; 111: 301-307.

34 Norris V, Choong L, Tran D, et al. Effect of IVL745, a VLA-4 antagonist, on allergen-induced bronchoconstriction in patients with asthma. J Allergy Clin Immunol 2005; 116: 761-767. 